\title{
Vulnerability Analysis for Reusing an Old Industrial Area: A Case Study of the Winter Olympic Park
}

\author{
Wei Tian $\left(\mathbb{D},{ }^{1}\right.$ Xingrun Zhong $\mathbb{D}^{2},{ }^{2}$ Ping Guo, ${ }^{1}$ and Guangmin Zhang ${ }^{1}$ \\ ${ }^{1}$ School of Civil Engineering, Xi'an University of Architecture and Technology, Xi'an 710055, China \\ ${ }^{2}$ School of Resources Engineering, Xi'an University of Architecture and Technology, Xi'an 710055, China \\ Correspondence should be addressed to Xingrun Zhong; zxj948145101@sina.com
}

Received 14 November 2020; Revised 5 February 2021; Accepted 8 March 2021; Published 26 March 2021

Academic Editor: Alessio Cascardi

Copyright (c) 2021 Wei Tian et al. This is an open access article distributed under the Creative Commons Attribution License, which permits unrestricted use, distribution, and reproduction in any medium, provided the original work is properly cited.

Reuse of old industrial areas strongly impacts urban renewal and social development. However, it is limited by significant pollution and damage of buildings. In the decision-making stage, it is necessary to conduct a reasonable vulnerability analysis of old industrial areas. This study focuses on establishing a reasonable and effective vulnerability assessment model to be used in actual work. First, based on literature analysis, a normal cloud model was employed to establish the assessment process and model. Second, foundation damage, structural bearing capacity, and other building safety indicators, as well as environmental safety, were included in the vulnerability assessment indicator system. Thus, through indicator selection and optimization, the vulnerability assessment indicators and their quantitative methods were determined and parameter features of the cloud model were programmed by the forward cloud generator. Finally, the Shougang Industrial Area, to be reused as the Winter Olympic Park, was selected as the case study. The vulnerability analysis results show that the vulnerability assessment method strongly agrees with the actual status and that the assessment results provide a basis for improving the vulnerability of old industrial areas for reuse.

\section{Introduction}

The reuse of old industrial areas in China began in the 1990s, before which most old industrial buildings were demolished and then used to develop real estate. With the adjustment of industrial structure usage, the number of idle industrial buildings increased in the 1990s. At the same time and inspired by high-quality reuse projects for old industrial areas abroad, the number of reuse projects has increased in China [1]. Beginning in the 21st century, environmental pollution caused by industrial manufacturing has become a major problem in China. To solve the conflicts between industrial pollution and urban environmental safety, many urban governments have required the shutdown or relocation of polluting industrial plants. With the constant expansion of cities, the industrial areas that were located at edges of cities have become downtown areas. Due to the improvements in environmental protection as well as the need for the cultural and spiritual sites, various reused industrial areas have become abundant in major cities.
Under the background of urban renewal, the reuse of old industrial areas needs to be reasonably and properly developed as it is also a type of reasonable protection for industrial areas with cultural values [2]. Therefore, it is crucial to determine how to develop these former industrial areas; however, this development is limited by the structural damage to existing buildings, actual pollution of sites, and the social influence and economic ability of developers. The buildings that are located in old industrial areas have been damaged and the soil, groundwater, and other environments have been all polluted. These damages and pollution have seriously affected the reuse of the old industrial areas. However, the irreplaceable historical and cultural values render the reuse of old industrial areas to be highly important for urban renewal. Therefore, it is significant to comprehensively assess whether old industrial areas have potential for reuse in society, economy, and while considering environmental and structural safety. Furthermore, vulnerability assessments can provide a basis for decision-makers. 
"Vulnerability assessment" first appeared in the study of natural disasters and has made great progress in economy, society, environment, and other aspects [3]. Vulnerability analysis has developed from natural disasters to multiple coupling systems and has formed comprehensive research in many different fields.

Currently, the primary research for vulnerabilities includes the following: quantitative assessment of ecological and environmental vulnerability [3]; urban vulnerability evolution [4]; social vulnerability assessment [5], and changed rules of urbanization vulnerability [6]. Liu et al. established a land eco-security assessment, which was based on the multidimensional connection cloud model that included natural environmental conditions, social development, and human sustainability [7]. Wang et al. comprehensively analyzed 139 social-economic-ecological system indicators and sustainable performance in Beijing from the perspective of urban resilience [8]. Through an emergency assessment, Zhang et al. observed the before and after differences for brownfield redevelopment of an old industrial area in Tiexi, China, and analyzed the key factors influencing brownfield redevelopment [9].

The methods used for vulnerability assessments depend on the characteristics of what is being assessed. Luan et al. used the Bayesian spatial factor analysis model to evaluate the environmental health of adjacent restaurants, but the fuzziness of the indicators led to deviations between the assessed and actual values [10]. The randomness of indicators is not solved by set pair analysis, gray correlation, or other fuzzy set theories, and there is a loss of fuzziness among indicators.

According to the fuzzy set theory, the membership function is used for set pair analysis and gray correlation. For the gray correlation model, the fuzzy comprehensive method cannot overcome index randomness [11].

Qualitative assessment methods have been used widely in many fields. Lee et al. proposed a system dynamics model to measure the function of product-service systems [12]. Yoon and Sim used literature analysis to qualitatively assess Korea's renewable energy policy [13]. However, due to the qualitative factors of those methods, the results always tended to be subjective.

In recent years, multi-method integrated assessment models have emerged in many studies such as the combination of factor analysis and cluster analysis methods [14], TOPSIS and fuzzy set theory [15], and the combination of qualitative and quantitative methods [16]. However, these integrated models cannot overcome their original flaws for each integrated model.

The normal cloud model proposed by $\mathrm{Li}$ is a useful method for transforming a qualitative concept into quantitative data and is a new graphical model that can synthetically plot the randomness and fuzziness of concepts [17]. Each cloud droplet represents the quantitative performance of a qualitative concept [18]. This theory has been widely applied to a large number of areas [19].

Different from conventional project development, the structural safety of building structures and environmental pollution at sites should be considered for reuse of old industrial areas. According to the reuse process of old industrial areas [2], industrial areas should first be investigated to assess their structural and environmental safety as well as their economic and social vulnerability. This study employed the normal cloud model, which can consider the randomness of statistical processes and fuzziness of inputs, established a vulnerability assessment indicator system through the Delphi method, used interval-based analysis hierarchy process ((IAHP) to determine the relative standard weight of indicators, and assessed the vulnerability of the Shougang Industrial Area of Beijing to improve the reuse of this old industrial area.

\section{Methodology}

2.1. Normal Cloud Model. Cloud models are an effective tool to transform uncertainties between qualitative and quantitative expression, and their expressions reflect the fuzziness and randomness of variables.

The normal cloud model (NCM) constructs random variables, cloud droplets, by introducing the expected value (Ex), entropy (En), and hyper entropy (He). Cloud droplets are generated by multiple calculations to form the normal cloud figure (Figure 1). Individual cloud droplets have no regularity but the greater the number of cloud droplets produced, the more prominent the overall characteristics of an indicator (qualitative concept).

Ex represents the central value of the cloud figure distribution and is the most representative point of qualitative concepts in the cloud figure [20]. En is an acceptable value range that reflects the dispersion of cloud droplets in the cloud figure. Relatively large En values mean that it is less likely that cloud droplets are accepted. He reflects the condensation of all cloud droplets and represents the cloud thickness. $n$ is the number of calculations (i.e., the number of cloud droplets).

NCM quantifies variables with qualitative concepts through the forward cloud generator to clarify fuzzy concepts and explain the correlations between randomness and fuzziness of variables. The steps for a vulnerability assessment by using the forward cloud generator are shown in Figure 2.

2.2. General Framework. In this study, the vulnerability assessment indicators for old industrial areas are built based on target, standard, and index levels. The target level is the vulnerability of the old industrial area to be reused and the standard level includes four aspects, namely, building structure, environment, society, and economy. The weight of each indicator is obtained through expert consultation and IAHP, as shown in Figure 3. The normal cloud model based on IAHP was used to assess the reuse vulnerability of old industrial areas, and its framework is shown in Figure 3.

\subsection{Assessment Model Based on IAHP-NCM}

2.3.1. Indicator Settings. The vulnerability assessment indicator system $U=\left\{u_{1}, u_{2}, \ldots, u_{n}\right\}$ and vulnerability level 


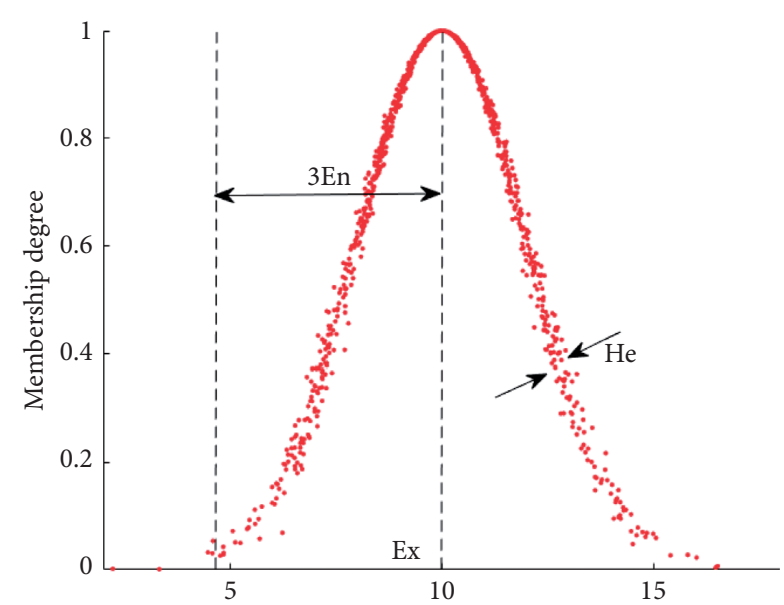

Figure 1: Normal cloud figure. $\mathrm{Ex}=10, \mathrm{En}=2, \mathrm{He}=0.1$, and $n=1000$

$V=\left\{v_{1}, v_{2}, v_{3}, v_{4}, v_{5}\right\}$ are established through literature analysis and expert consultation. The vulnerability level in this study includes five levels: low vulnerability (I), relatively low vulnerability (II), middle vulnerability (III), relatively high vulnerability (IV), and high vulnerability (V). $n$ represents the number of indicators.

2.3.2. Weights of Assessment Indicators. To reduce the uncertainty and subjectivity of indicator weights, IAHP was selected to determine indicator weights, which is a method to solve the uncertainty and fuzziness for the case of incomplete information, and combines qualitative and quantitative analyses. Its steps are similar to those of AHP. The difference is that point values are replaced by interval numbers to establish the judgment matrix. Furthermore, IAHP reflects the fuzziness and uncertainty of the assessment process and makes the assessment results more reasonable and reliable [21].

2.3.3. Cloud Parameters. It is assumed that at a certain vulnerability level, the upper and lower limit values of the threshold of the index $x_{i j}$ are, respectively, $x_{i j}^{1}$ and $x_{i j}^{2}$. Ex can be calculated by

$$
\mathrm{Ex}=\frac{x_{i j}^{1}+x_{i j}^{2}}{2} .
$$

En can be calculated by

$$
\mathrm{En}=\frac{\left|x_{i j}^{1}-x_{i j}^{2}\right|}{2.355} \text {. }
$$

He is generally determined by the experiment, which is 0.01 in this study.

In this study, the cloud parameters (Ex, En, and $\mathrm{He}$ ) of the assessment indicators were input into the forward cloud generator to calculate the membership degree $y=$ $e^{-(x-E \mathrm{Ex})^{2} / 2\left(E^{\prime} n\right)^{2}}$ of an assessment indicator. According to the number of indicators and reliability of results, the cyclic forward cloud generator used 2, 000 as the number of cycles,

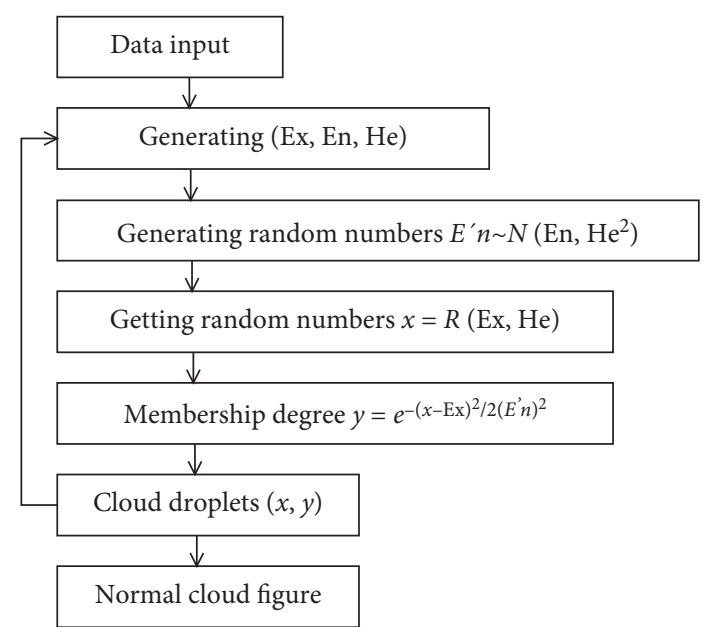

Figure 2: Operation of the forward cloud generator.

which yielded $r_{i j}=\sum_{k=1}^{2000} r_{i j}^{k} / 2000$ as the membership degree, and the indicator membership matrix $\mathbf{R}$ is formed. The element $r_{i j}$ in the membership matrix represents the membership degree, which corresponds to the $v_{j \text {-level }}$ of the indicator $u_{i}$.

2.3.4. Assessment Results. The membership matrix $\mathbf{R}$ and weight set $W$ are used for the fuzzy transformation to obtain the fuzzy subset $B=W \cdot \mathbf{R}=\left(b_{1}, b_{2}, \ldots, b_{n}\right)$ of the vulnerability level $V . \quad b_{j}=\sum_{i=1}^{n} w_{i} \times r_{i j}, j=1,2,3,4,5$ is the membership degree of the assessment object at the $j$ level. The vulnerability level, which corresponds to the maximum membership degree, is selected as the assessment result according to the calculations.

\section{Establishment of the Indicator System}

3.1. Indicator Selection. Compared with traditional assessment methods, the concept of the normal cloud model reflects the essence of assessment indicators in a better way. Moreover, to conform to the calculation rules of the forward cloud generator, the calculation methods of indicator values and assessment standards of indicators are set, which can reduce the influence of fuzziness and randomness of indicators on the assessment results. On the one hand, the assessment indicators should reflect the vulnerability of old industrial areas in the entire process of decision-making, design, construction, and operation. On the other hand, it should be able to show the trend of vulnerability.

3.1.1. Primary Selection of Indicators. This study uses buildings, environment, society, and the economy as the assessment objects; selects 30 investigation reports from onsite observations and interviews, ten structural inspection reports of old industrial buildings, and five environmental impact assessment reports of old industrial areas as the original database; and conducts literature analysis to collect and summarize the initial framework of the vulnerability 


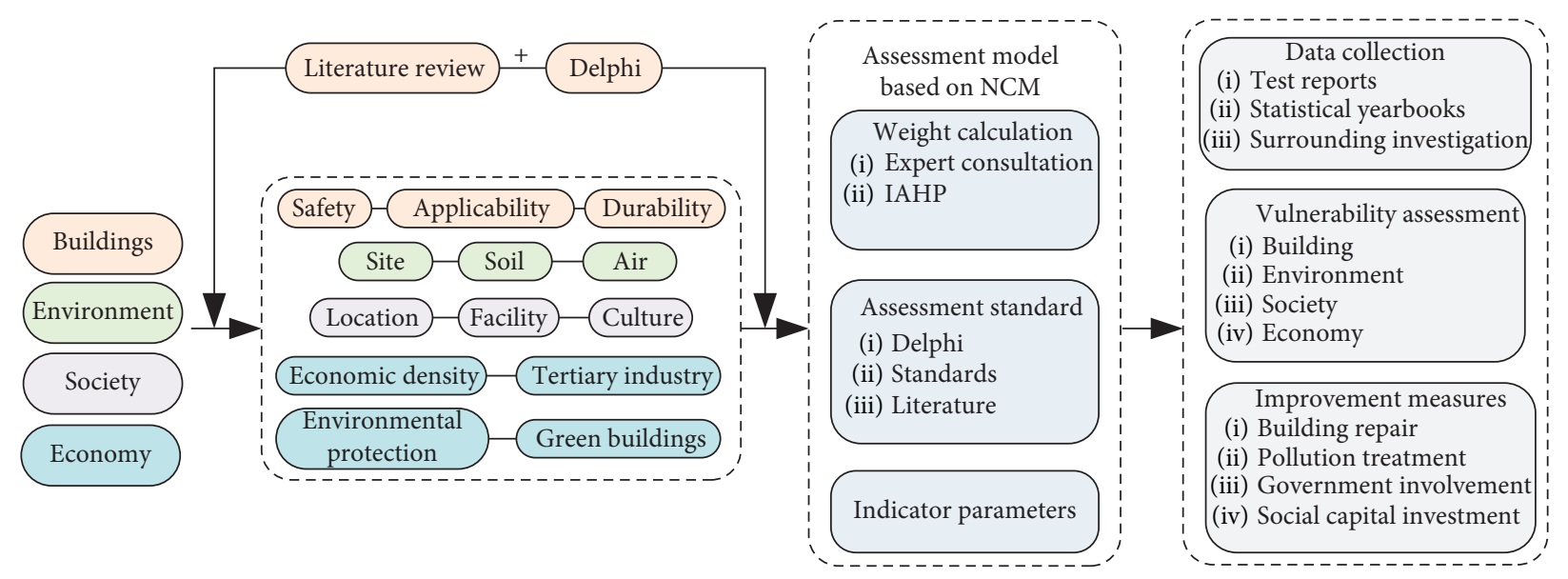

Figure 3: Framework.

assessment indicator system for old industrial areas to be reused.

\subsubsection{Optimization of the Initial Indicator Framework.} In this study, experts in this field (3 professors, 4 structural engineers, 3 environmental engineers, and 3 related government personnel) were selected to supplement and optimize the indicator system by the Delphi method and by brainstorming. These methods can increase expert understanding of the vulnerability of old industrial areas for reuse, which can not only refine the meanings of indicators but can also help to avoid misjudgment of valid indicators. After repeated screening and optimization, the vulnerability assessment indicator system for old industrial areas to be reused was determined, as shown in Table 1.

\subsection{Assignment of Assessment Indicators}

3.2.1. Vulnerability Assessment Level. After a large number of environmental investigations, structural inspections, and case analyses in old industrial areas, the structural damage to old industrial building structures and environmental pollution levels of old industrial areas should be considered in the vulnerability analysis. Based on the decomposition and comparative analysis of the characteristics and vulnerabilities of old industrial areas, the vulnerability assessment level, $s$, is determined. Therefore, this study classifies the vulnerability level for reusing old industrial areas into five levels: low vulnerability (I), relatively low vulnerability (II), moderate vulnerability (III), relatively high vulnerability (IV), and high vulnerability (V).

3.2.2. Setting Indicator Thresholds. Based on a comprehensive analysis of the relevant literature and expert opinions and by referring to relevant structural inspections and environmental monitoring standards, the threshold values of all indicators under the vulnerability level are defined, as shown in Table 2.
3.2.3. Setting of Indicator Parameters. Regarding the thresholds of vulnerability assessment indicators, there is only a one-sided limit for the thresholds of some indicators, namely, the single-boundary variables $\left[-\infty, C_{\max }\right)$ and $\left[C_{\text {min }},+\infty\right)$. In this case, if the indicator value rises with an increase of the vulnerability level, the upper threshold of the indicator within this level is: $C_{\max }=\mathrm{Ex}^{\mathrm{IV}}+\left(\mathrm{Ex}^{\mathrm{IV}}-C_{\min }{ }^{\mathrm{III}}\right)$, and the expected value of the indicator at this level is: $\mathrm{Ex}=\left(2 \mathrm{Ex}^{\mathrm{IV}}-C_{\min }{ }^{\mathrm{III}}-x_{i j}^{\mathrm{I}}\right) / 2$. If the indicator value decreases with an increase of vulnerability, the upper threshold of the indicator within this level is: $C_{\max }=\mathrm{Ex}^{\mathrm{II}}+$ $\left(\mathrm{Ex}^{\mathrm{II}}-C_{\min }{ }^{\mathrm{III}}\right)$. The expected value of the indicator at this level is: $\mathrm{Ex}=\left(2 \mathrm{Ex}^{\mathrm{II}}-C_{\min }{ }^{\mathrm{III}}-x_{i j}^{\mathrm{I}}\right) / 2$. The normal cloud parameters (Ex, En, and $\mathrm{He}$ ) of the vulnerability assessment indicators for reusing old industrial areas are calculated based on MATLAB (the forward cloud generator is cycled 2, 000 times), as shown in Table 3.

\section{Vulnerability Analysis for Reusing Shougang Industrial Area}

4.1. Shougang Industrial Area and the Winter Olympic Park. Shougang Industrial Area was founded in 1919, which was one of the largest steel mills in China and is located in the Shijingshan District of Beijing. In 2005, the Shougang Group began to relocate, and in 2008, it was shut down and had completely relocated from Beijing to comply with the requirements for a "Green Olympics." Therefore, much of the industrial land was idle. In July 2015, Beijing was officially selected to be the host city of the 24th Olympic Winter Games. The Beijing municipal government and the organizing committee of the Olympic Games (BOCOG) agreed to utilize the old industrial area of Shougang as the offices and venues for the BOCOG, as is shown in Figure 4. The reuse of Shougang Industrial Park restored the environment, saved land resources, and protected the industrial heritage, which matches the concepts and requirements of the Beijing Winter Olympic Games.

4.2. Buildings and Site Environment. The buildings in this area were constructed at various times with different kinds of structures, but the structural type of these buildings is 
TABLE 1: The vulnerability assessment indicator system for reusing old industrial areas.

\begin{tabular}{|c|c|c|c|c|}
\hline Target layer & & Criteria layer & Type & Interpretation and calculation \\
\hline Building & Applicability $x_{2}$ & $\begin{array}{c}\text { Foundation damage } x_{11} \\
\text { Structural-bearing capacity } x_{12} \\
\text { Structure tilting } x_{13} \\
\text { Structure strength } x_{14} \\
\text { Structural impact resistance } x_{15} \\
\text { Load-bearing structural member } x_{21} \\
\text { Stressed crack } x_{22} \\
\text { Building envelope } x_{23} \\
\text { Existing pipeline } x_{24} \\
\text { Concrete cover } x_{31} \\
\text { Structure durability } x_{32} \\
\text { Column bracing } x_{33}\end{array}$ & $\begin{array}{l}+ \\
- \\
+ \\
- \\
- \\
+ \\
+ \\
+ \\
+ \\
- \\
- \\
-\end{array}$ & $\begin{array}{c}\text { Damage quantity/total inspections } \\
\text { Qualified members/total inspections } \\
\text { Transfinite structures/total inspections } \\
\text { Qualified members/total inspections } \\
\text { (Total area-frame structure area)/total area } \\
\text { Damaged members/total inspections } \\
\text { Stressed cracks/total cracks } \\
\text { Damage area/total area } \\
\text { Damage length/total length } \\
\text { Qualified number/total inspections } \\
\text { Durability life/service life } \\
\text { Existing bracing/design bracing number }\end{array}$ \\
\hline Environment & Soil $X_{5}$ & $\begin{array}{c}\text { Building density } x_{41} \\
\text { Energy of hazardous substances } x_{42} \\
\text { Toxicant hazard } x_{43} \\
\text { Polluted structural members } x_{44} \\
\text { Polluted area } x_{45} \\
\text { Noise pollution } x_{46} \\
\text { Greening } x_{47} \\
\text { Heavy metals } x_{51} \\
\text { Organic matter } x_{52} \\
\text { Ground water } x_{53} \\
\text { Polluting plants area } x_{61} \\
\text { Air quality } x_{62} \\
\end{array}$ & $\begin{array}{l}- \\
+ \\
+ \\
+ \\
+ \\
+ \\
- \\
+ \\
+ \\
+ \\
+ \\
+\end{array}$ & $\begin{array}{c}\text { Building area/total area } \\
\text { Number of hazardous chemicals } \\
\text { Standard of GBZ 230-2010 } \\
\text { Polluted members/total inspections } \\
\text { Polluted area/total area } \\
\text { Proportion of excess noise } \\
\text { Greening area/total area } \\
\text { Heavy metal concentration, according to the EIA report } \\
\text { Organic matter concentration, according to the EIA report } \\
\text { Water qualification rate } \\
\text { Polluting plants area/regional area } \\
\text { Percentage of good air }\end{array}$ \\
\hline Society & Location $X_{7}$ & $\begin{array}{c}\text { Road network } x_{71} \\
\text { Traffic convenience } x_{72} \\
\text { Population } x_{73} \\
\text { Business } x_{74} \\
\text { Infrastructure } x_{81} \\
\text { Living facilities } x_{82} \\
\text { Factory history } x_{91}\end{array}$ & $\begin{array}{l}- \\
- \\
- \\
-\end{array}$ & $\begin{array}{c}\text { Road mileage/regional area } \\
\text { Number of bus stops } \\
\text { Population density } \\
\text { Business density } \\
\text { Infrastructures area/regional area } \\
\text { Living facilities area/regional area } \\
\text { Factory years } \\
\end{array}$ \\
\hline Economy $X_{10}$ & Envi & $\begin{array}{l}\text { Economic density } x_{101} \\
\text { Tertiary industry } x_{102} \\
\text { ironmental protection } x_{103} \\
\text { Green buildings } x_{104}\end{array}$ & $\begin{array}{l}- \\
- \\
- \\
-\end{array}$ & $\begin{array}{c}\text { Local GDP/regional area } \\
\text { Tertiary industry scale/total scale } \\
\text { Environmental protection investment/total investment } \\
\text { Number of green buildings/total number }\end{array}$ \\
\hline
\end{tabular}

Note. "+" and "-" indicate that the indicator has a positive or negative effect on the reuse vulnerability level.

mainly frame construction. Most buildings were damaged to different degrees due to the characteristics of the steel-processing works. The status of some buildings is shown in Figure 5.

Furthermore, owing to a lack of maintenance, many structures and facilities were damaged and the plants were overgrown with weeds, as shown in Figures 6 and 7.

Although the production processes of the Shougang Group were very mature and many types of sewage systems had been built after many years of development, the factory had a long production period. Consequently, large amounts of waste gas with dust and organic pollutants from furnaces and the soil of the park and industrial wastewater were not disposed of properly and caused further soil pollution as well.

4.3. Data Collection. According to the vulnerability assessment indicator system and the assessment model for reusing old industrial areas, the indicator input data were obtained by means of test reports, local statistical yearbooks, and surrounding environmental investigations: (1) most of the vulnerability assessment inputs for the structural safety and environmental safety indicators came from structural safety inspection reports and environmental monitoring reports, which were an important source for obtaining input data; (2) the input data of some social vulnerability and economic vulnerability indicators such as economic density and tertiary industries were obtained by browsing and checking the information and local statistical yearbooks that were published on local government websites; and (3) the input data of some indicators had to be collected by deeply investigating the surrounding social, economic, and environmental situations.

4.4. Building Vulnerability Assessment. Based on the vulnerability assessment model established in Section 2.3 and indicator input data, the membership degree and normal cloud figure of each vulnerability indicator were calculated and plotted. The assessment input data for the building vulnerability indicators are shown in Table 4 . 
TABLE 2: Thresholds of vulnerability assessment indicators for reusing old industrial areas.

\begin{tabular}{|c|c|c|c|c|c|c|}
\hline Indicator level & Weights & I & II & III & IV & $\mathrm{V}$ \\
\hline$x_{11}$ & 0.233 & $(0,0.15)$ & $(0.15,0.3)$ & $(0.3,0.45)$ & $(0.45,0.6)$ & $(0.6,1)$ \\
\hline$x_{12}$ & 0.315 & $(0.6,1)$ & $(0.3,0.6)$ & $(0.2,0.3)$ & $(0.1,0.2)$ & $(0,0.1)$ \\
\hline$x_{13}$ & 0.122 & $(0,0.1)$ & $(0.1,0.2)$ & $(0.2,0.3)$ & $(0.3,0.6)$ & $(0.6,1)$ \\
\hline$x_{14}$ & 0.144 & $(0.3,1)$ & $(0.15,0.3)$ & $(0.1,0.15)$ & $(0.05,0.1)$ & $(0,0.05)$ \\
\hline$x_{15}$ & 0.186 & $(0.7,1)$ & $(0.3,0.7)$ & $(0.2,0.3)$ & $(0.1,0.2)$ & $(0,0.1)$ \\
\hline$x_{21}$ & 0.352 & $(0,0.05)$ & $(0.05,0.1)$ & $(0.1,0.15)$ & $(0.15,0.3)$ & $(0.3,1)$ \\
\hline$x_{22}$ & 0.279 & $(0,0.05)$ & $(0.05,0.1)$ & $(0.1,0.15)$ & $(0.15,0.3)$ & $(0.3,1)$ \\
\hline$x_{23}$ & 0.225 & $(0,0.1)$ & $(0.1,0.2)$ & $(0.2,0.3)$ & $(0.3,0.4)$ & $(0.4,1)$ \\
\hline$x_{24}$ & 0.144 & $(0,0.2)$ & $(0.2,0.4)$ & $(0.4,0.6)$ & $(0.6,0.8)$ & $(0.8,1)$ \\
\hline$x_{31}$ & 0.397 & $(0.9,1)$ & $(0.8,0.9)$ & $(0.7,0.8)$ & $(0.6,0.7)$ & $(0,0.6)$ \\
\hline$x_{32}$ & 0.344 & $(0.8,1)$ & $(0.6,0.8)$ & $(0.4,0.6)$ & $(0.2,0.4)$ & $(0,0.2)$ \\
\hline$x_{33}$ & 0.259 & $(0.8,1)$ & $(0.6,0.8)$ & $(0.4,0.6)$ & $(0.2,0.4)$ & $(0,0.2)$ \\
\hline$x_{41}$ & 0.104 & $(0.5,1)$ & $(0.3,0.5)$ & $(0.2,0.3)$ & $(0.1,0.2)$ & $(0,0.1)$ \\
\hline$x_{42}$ & 0.142 & $(0,5)$ & $(5,10)$ & $(10,50)$ & $(50,100)$ & $(100, \infty)$ \\
\hline$x_{43}$ & 0.153 & $(0,10)$ & $(10,35)$ & $(35,50)$ & $(50,65)$ & $(65, \infty)$ \\
\hline$x_{44}$ & 0.176 & $(0,0.1)$ & $(0.1,0.2)$ & $(0.2,0.3)$ & $(0.3,0.4)$ & $(0.4,1)$ \\
\hline$x_{45}$ & 0.221 & $(0,0.1)$ & $(0.1,0.2)$ & $(0.2,0.3)$ & $(0.3,0.4)$ & $(0.4,1)$ \\
\hline$x_{46}$ & 0.101 & $(0,0.3)$ & $(0.3,0.5)$ & $(0.5,0.7)$ & $(0.7,0.9)$ & $(90,120)$ \\
\hline$x_{47}$ & 0.103 & $(0.5,1)$ & $(0.4,0.5)$ & $(0.3,0.4)$ & $(0.2,0.3)$ & $(0.1,0.2)$ \\
\hline$x_{51}$ & 0.353 & $(0,0.2)$ & $(0.2,0.3)$ & $(0.3,0.6)$ & $(0.6,1)$ & $(1, \infty)$ \\
\hline$x_{52}$ & 0.278 & $(0,0.32)$ & $(0.32,0.64)$ & $(0.64,1)$ & $(1,4)$ & $(4, \infty)$ \\
\hline$x_{53}$ & 0.369 & $(0,0.6)$ & $(0.6,0.7)$ & $(0.7,0.8)$ & $(0.8,0.9)$ & $(0.9,1)$ \\
\hline$x_{61}$ & 0.674 & $(1,2)$ & $(2,5)$ & $(5,10)$ & $(10,15)$ & $(15, \infty)$ \\
\hline$x_{62}$ & 0.326 & $(1,0.9)$ & $(0.9,0.7)$ & $(0.7,0.5)$ & $(0.5,0.3)$ & $(0.3,0)$ \\
\hline$x_{71}$ & 0.268 & $(6.6,5)$ & $(5,4)$ & $(4,3)$ & $(3,2)$ & $(2,0)$ \\
\hline$x_{72}$ & 0.179 & $(20,16)$ & $(16,12)$ & $(12,8)$ & $(8,4)$ & $(4,0)$ \\
\hline$x_{73}$ & 0.221 & $(200,100)$ & $(100,50)$ & $(50,25)$ & $(25,1)$ & $(1,0)$ \\
\hline$x_{74}$ & 0.332 & $(1,0.4)$ & $(0.4,0.3)$ & $(0.3,0.2)$ & $(0.2,0.1)$ & $(0.1,0)$ \\
\hline$x_{81}$ & 0.478 & $(1,0.4)$ & $(0.4,0.3)$ & $(0.3,0.2)$ & $(0.2,0.1)$ & $(0.1,0)$ \\
\hline$x_{82}$ & 0.522 & $(1,0.3)$ & $(0.3,0.25)$ & $(0.25,0.2)$ & $(0.2,0.15)$ & $(0.15,0)$ \\
\hline$x_{91}$ & 1 & $(100,40)$ & $(40,30)$ & $(30,20)$ & $(20,10)$ & $(10,0)$ \\
\hline$x_{101}$ & 0.399 & $(12,8)$ & $(8,4)$ & $(4,2)$ & $(2,1)$ & $(1,0)$ \\
\hline$x_{102}$ & 0.159 & $(1,0.5)$ & $(0.5,0.4)$ & $(0.4,0.3)$ & $(0.3,0.2)$ & $(0.2,0)$ \\
\hline$x_{103}$ & 0.286 & $(1,0.4)$ & $(0.4,0.3)$ & $(0.3,0.2)$ & $(0.2,0.1)$ & $(0.1,0)$ \\
\hline$x_{104}$ & 0.155 & $(1,0.8)$ & $(0.8,0.6)$ & $(0.6,0.4)$ & $(0.4,0.2)$ & $(0.2,0)$ \\
\hline
\end{tabular}

Note. In this study, the assessed objects are reinforced concrete buildings, the height of the factory building is $30 \mathrm{~m}$, the heavy metal is cadmium, and the organic material is benzene. These are very common in old industrial areas.

The vulnerability membership degree of each indicator was calculated by NCM, as shown in Table 5 . The cloud figure of each indicator was generated by the forward cloud generator, as shown in Figure 8.

There is a tendency in the membership degree of vulnerability of some indicators, in which the membership degree of "structure tilting" $x_{13}$ is clear and belongs to level II, but the vulnerability of "concrete cover" $x_{31}$ belongs to level III and tends to level II.

By dimensionless processing of the index assessment values with different attributes, the indexes with high vulnerability can be better judged in a coordinate system.

\section{(1) Safety}

According to the results of the vulnerability assessment, the building safety of the old industrial area is level II tending to level I, with low vulnerability. However, there are some cases of foundation damage, e.g., insufficient strength and decreased bearing capacity, which were mainly caused by the corrosivity of acid soils. The structural-bearing capacity of most buildings meets the requirements while some structures, such as slag pools, partially malfunction due to the action of acids or lack of repairs. Affected by foundation damage and loads during the production period, some columns and load-bearing walls have inclined. Around $78.6 \%$ of the structural strengths meet the requirements of the inspection standards and $68.6 \%$ of the buildings in the complex are concrete frame structures with strong impact resistance, which represents good conditions in many similar buildings.

(2) Applicability

All assessment values for building applicability are relatively high. Despite the relatively low building safety, $21.8 \%$ of load-bearing members have been damaged to some extent mainly due to insufficient maintenance during production. Moreover, stress cracks account for a small proportion but present relatively high levels of vulnerability. There is much breakage of enclosure structures and existing 
TABLE 3: Normal cloud parameters of vulnerability assessment indicators for reusing old industrial areas.

\begin{tabular}{|c|c|c|c|c|c|}
\hline & $\mathrm{I}$ & II & III & IV & $\mathrm{V}$ \\
\hline$x_{11}$ & $(0.075,0.06,0.01)$ & $(0.225,0.06,0.01)$ & $(0.375,0.06,0.01)$ & $(0.525,0.06,0.01)$ & $(0.8,0.17,0.01)$ \\
\hline$x_{12}$ & $(0.8,0.17,0.01)$ & $(0.45,0.13,0.01)$ & $(0.25,0.04,0.01)$ & $(0.15,0.04,0.01)$ & $(0.05,0.04,0.01)$ \\
\hline$x_{13}$ & $(0.05,0.04,0.01)$ & $(0.15,0.04,0.01)$ & $(0.25,0.04,0.01)$ & $(0.45,0.13,0.01)$ & $(0.8,0.17,0.01)$ \\
\hline$x_{14}$ & $(0.65,0.3,0.01)$ & $(0.225,0.06,0.01)$ & $(0.125,0.02,0.01)$ & $(0.075,0.02,0.01)$ & $(0.025,0.02,0.01)$ \\
\hline$x_{15}$ & $(0.85,0.13,0.01)$ & $(0.5,0.17,0.01)$ & $(0.25,0.04,0.01)$ & $(0.15,0.04,0.01)$ & $(0.05,0.04,0.01)$ \\
\hline$x_{21}$ & $(0.025,2.12,0.01)$ & $(0.075,2.12,0.01)$ & $(0.125,2.12,0.01)$ & $(0.225,6.37,0.01)$ & $(0.65,29.72,0.01)$ \\
\hline$x_{22}$ & $(0.025,2.12,0.01)$ & $(0.075,2.12,0.01)$ & $(0.125,2.12,0.01)$ & $(0.225,6.37,0.01)$ & $(0.65,29.72,0.01)$ \\
\hline$x_{23}$ & $(0.05,0.04,0.01)$ & $(0.15,0.04,0.01)$ & $(0.25,0.04,0.01)$ & $(0.35,0.04,0.01)$ & $(0.7,0.25,0.01)$ \\
\hline$x_{24}$ & $(10,8.49,0.01)$ & $(30,8.49,0.01)$ & $(50,8.49,0.01)$ & $(70,8.49,0.01)$ & $(90,8.49,0.01)$ \\
\hline$x_{31}$ & $(95,4.25,0.01)$ & $(85,4.25,0.01)$ & $(75,4.25,0.01)$ & $(65,4.25,0.01)$ & $(30,25.48,0.01)$ \\
\hline$x_{32}$ & $(90,8.49,0.01)$ & $(70,8.49,0.01)$ & $(50,8.49,0.01)$ & $(30,8.49,0.01)$ & $(10,8.49,0.01)$ \\
\hline$x_{33}$ & $(90,8.49,0.01)$ & $(70,8.49,0.01)$ & $(50,8.49,0.01)$ & $(30,8.49,0.01)$ & $(10,8.49,0.01)$ \\
\hline$x_{41}$ & $(0.75,0.21,0.01)$ & $(0.4,0.08,0.01)$ & $(0.25,0.04,0.01)$ & $(0.15,0.04,0.01)$ & $(0.05,0.04,0.01)$ \\
\hline$x_{42}$ & $(2.5,2.12,0.01)$ & $(7.5,2.12,0.01)$ & $(30,16.99,0.01)$ & $(75,21.23,0.01)$ & $(120,16.99,0.01)$ \\
\hline$x_{43}$ & $(5,4.25,0.01)$ & $(22.5,10.62,0.01)$ & $(42.5,6.37,0.01)$ & $(57.5,6.37,0.01)$ & $(72.5,6.37,0.01)$ \\
\hline$x_{44}$ & $(0.05,0.04,0.01)$ & $(0.15,0.04,0.01)$ & $(0.25,0.04,0.01)$ & $(0.35,0.04,0.01)$ & $(0.7,0.25,0.01)$ \\
\hline$x_{45}$ & $(0.05,0.04,0.01)$ & $(0.15,0.04,0.01)$ & $(0.25,0.04,0.01)$ & $(0.35,0.04,0.01)$ & $(0.7,0.25,0.01)$ \\
\hline$x_{46}$ & $(15,12.74,0.01)$ & $(40,8.49,0.01)$ & $(60,8.49,0.01)$ & $(80,8.49,0.01)$ & $(105,12.74,0.01)$ \\
\hline$x_{47}$ & $(75,21.23,0.01)$ & $(45,4.25,0.01)$ & $(35,4.25,0.01)$ & $(25,4.25,0.01)$ & $(15,4.25,0.01)$ \\
\hline$x_{51}$ & $(0.1,0.08,0.01)$ & $(0.25,0.04,0.01)$ & $(0.45,0.13,0.01)$ & $(0.8,0.17,0.01)$ & $(1.15,0.13,0.01)$ \\
\hline$x_{52}$ & $(0.16,0.14,0.01)$ & $(0.48,0.14,0.01)$ & $(0.82,0.15,0.01)$ & $(2.5,1.27,0.01)$ & $(4.18,0.15,0.01)$ \\
\hline$x_{53}$ & $(95,4.25,0.01)$ & $(85,4.25,0.01)$ & $(75,4.25,0.01)$ & $(65,4.25,0.01)$ & $(30,25.48,0.01)$ \\
\hline$x_{61}$ & $(1.5,0.42,0.01)$ & $(3.5,1.27,0.01)$ & $(7.5,2.12,0.01)$ & $(12.5,2.12,0.01)$ & $(17.5,2.12,0.01)$ \\
\hline$x_{62}$ & $(0.95,0.04,0.01)$ & $(0.8,0.08,0.01)$ & $(0.6,0.08,0.01)$ & $(0.4,0.08,0.01)$ & $(0.15,0.13,0.01)$ \\
\hline$x_{71}$ & $(5.8,0.68,0.01)$ & $(4.5,0.42,0.01)$ & $(3.5,0.42,0.01)$ & $(2.5,0.42,0.01)$ & $(1,0.85,0.01)$ \\
\hline$x_{72}$ & $(18,1.7,0.01)$ & $(14,1.7,0.01)$ & $(10,1.7,0.01)$ & $(6,1.7,0.01)$ & $(2,1.7,0.01)$ \\
\hline$x_{73}$ & $(150,42.46,0.01)$ & $(75,21.23,0.01)$ & $(37.5,10.62,0.01)$ & $(13,10.19,0.01)$ & $(0.5,0.42,0.01)$ \\
\hline$x_{74}$ & $(0.7,0.25,0.01)$ & $(0.35,0.04,0.01)$ & $(0.25,0.04,0.01)$ & $(0.15,0.04,0.01)$ & $(0.05,0.04,0.01)$ \\
\hline$x_{81}$ & $(0.7,0.25,0.01)$ & $(0.35,0.04,0.01)$ & $(0.25,0.04,0.01)$ & $(0.15,0.04,0.01)$ & $(0.05,0.04,0.01)$ \\
\hline$x_{82}$ & $(0.65,0.3,0.01)$ & $(0.275,0.02,0.01)$ & $(0.225,0.02,0.01)$ & $(0.175,0.02,0.01)$ & $(0.075,0.06,0.01)$ \\
\hline$x_{91}$ & $(70,25.48,0.01)$ & $(35,4.25,0.01)$ & $(25,4.25,0.01)$ & $(15,4.25,0.01)$ & $(5,4.25,0.01)$ \\
\hline$x_{101}$ & $(10,1.7,0.01)$ & $(6,1.7,0.01)$ & $(3,0.85,0.01)$ & $(1.5,0.42,0.01)$ & $(0.5,0.42,0.01)$ \\
\hline$x_{102}$ & $(0.75,0.21,0.01)$ & $(0.45,0.04,0.01)$ & $(0.35,0.04,0.01)$ & $(0.25,0.04,0.01)$ & $(0.1,0.08,0.01)$ \\
\hline$x_{103}$ & $(0.7,0.25,0.01)$ & $(0.35,0.04,0.01)$ & $(0.25,0.04,0.01)$ & $(0.15,0.04,0.01)$ & $(0.05,0.04,0.01)$ \\
\hline$x_{104}$ & $(0.9,0.08,0.01)$ & $(0.7,0.08,0.01)$ & $(0.5,0.08,0.01)$ & $(0.3,0.08,0.01)$ & $(0.1,0.08,0.01)$ \\
\hline
\end{tabular}

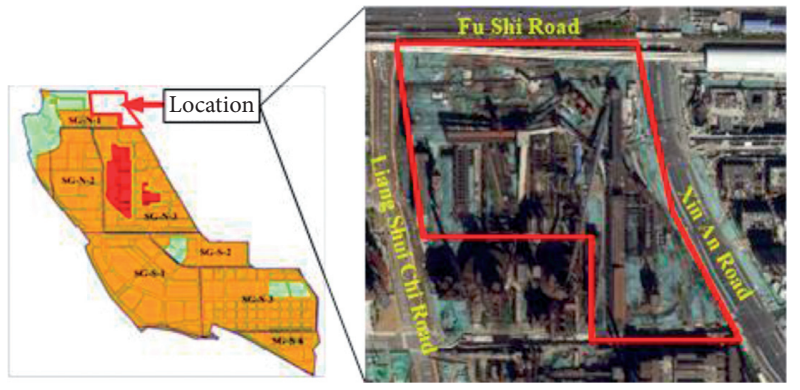

FIGURE 4: Plot of the project.

pipeline networks, and most of this has impacted doors and windows while the existing pipeline networks are greatly damaged because of the durability of pipeline materials was exceeded.

(3) Durability

Around $78.8 \%$ of the tested concrete covers meet the standards and have a relatively low vulnerability level. As buildings in the complex were built in the 1970s and 1990s, some buildings have been used for more than half of their design service life. The retention rate of column bracings in the industrial buildings is high at $78.1 \%$.

4.5. Environmental Vulnerability Assessment. The assessment values of the environmental vulnerability indicators were obtained from the results of environmental monitoring reports and surrounding environmental investigations, as shown in Table 6.

Due to the characteristics of the production process and environmental pollution in the industrial area, the assessment values of some indicators are high.

Based on NCM, the vulnerability membership degree of each indicator was calculated, as shown in Table 7. The cloud figure of assessment values and standard normal cloud figure of each indicator were generated by the forward cloud generator, as shown in Figure 9.

4.5.1. Site. The assessment value of the indicator "energy of hazardous substances," $x_{42}$, is 31 based on environmental monitoring reports, which indicate that there are many hazardous substances left by the original industrial 


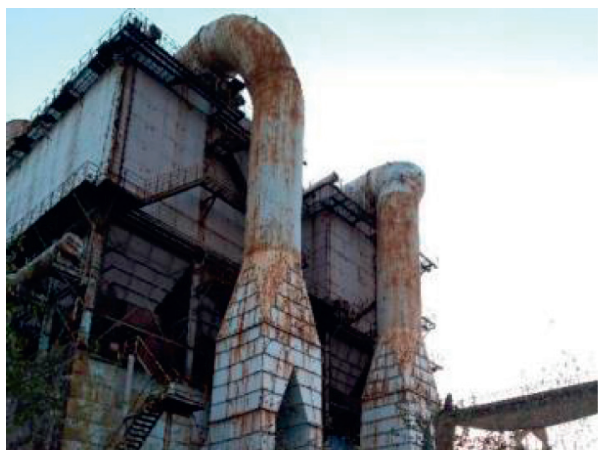

(a)

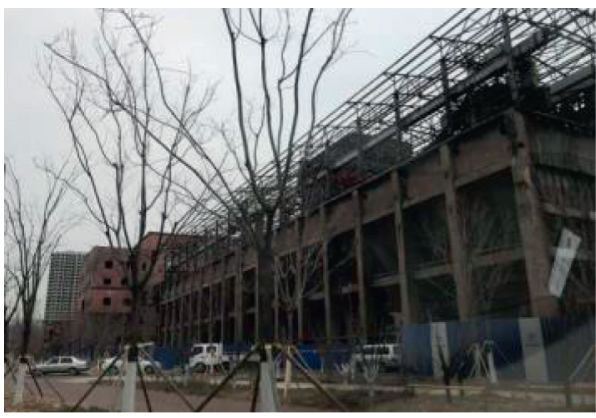

(c)

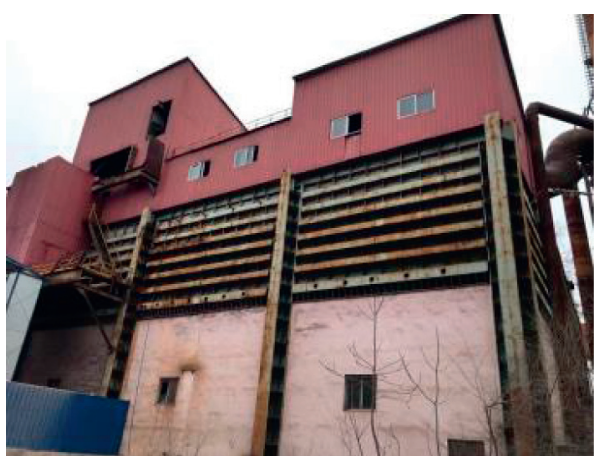

(b)

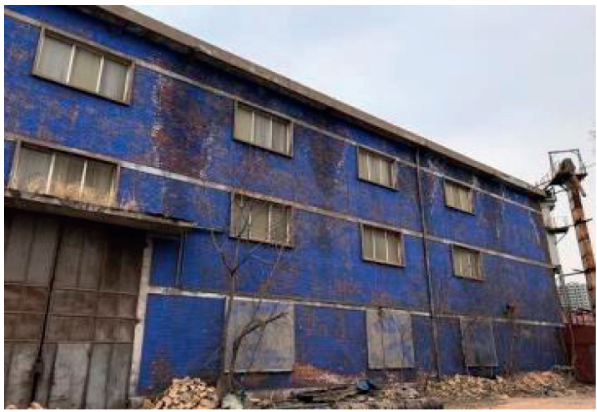

(d)

FIgure 5: Status of some buildings. (a) Blast furnace with dedusting. (b) Warehouse. (c) Transfer station. (d) Spare parts warehouse.

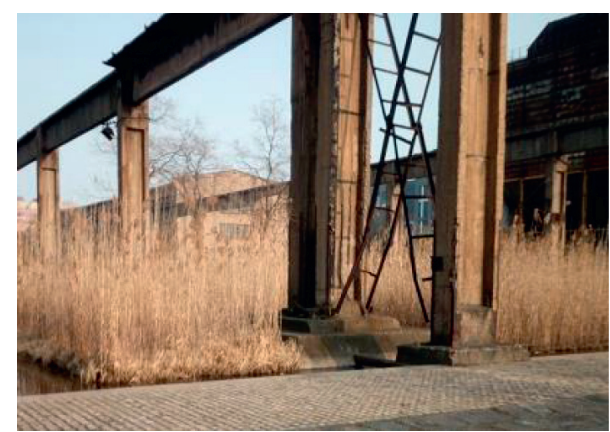

Figure 6: A corner of the factory.

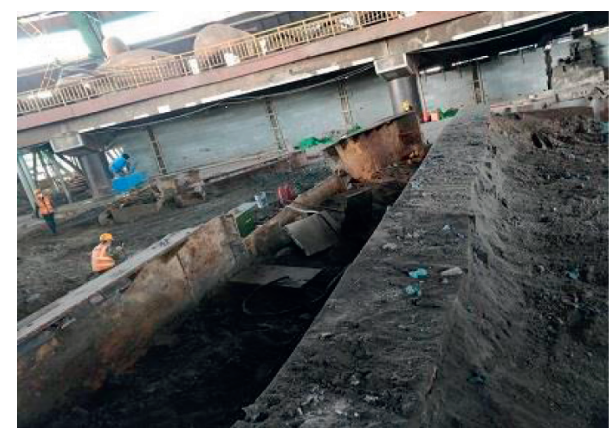

FIgURE 7: The slag outlet of a blast furnace.

production. Therefore, the indicator "polluted structural members," $x_{44}$, and the indicator "polluted area," $x_{45}$, are also at relatively high vulnerability levels. Owing to the special production processes, the distances between buildings are wide and building density is low. The area is large, and the buildings are far from city roads, so the noise is low. Greening comes from the original industrial area, which has a large number of tall and large trees.

4.5.2. Soil. According to the environmental monitoring report, the concentration of soil pollutants is high and over the established limits, but the pollution distribution is centralized. The distributions of heavy metal pollution, organic matter pollution, and groundwater pollution are similar and are mainly distributed near the blast furnace with dedusting and near the wastewater tank.

4.5.3. Air. This area is located in the industrial district of Beijing. Although most factories were moved during the 2008 Olympic Games, there are still a few polluting plants in this area. Furthermore, because it is affected by the Beijing-Tianjin-Hebei Industrial Zone, the air quality is relatively average.

4.6. Social Vulnerability Assessment. The assessment input data of social vulnerability indicators based on local statistics and surrounding social investigations are shown in Table 8.

The vulnerability membership degree of each indicator was calculated by NCM, as shown in Table 9. The standard normal cloud figure for each indicator was generated by the forward cloud generator, as shown in Figure 10. 
TABLE 4: Assessment inputs of building vulnerability indicators.

\begin{tabular}{|c|c|c|c|c|c|c|c|c|c|c|c|c|}
\hline \multirow{2}{*}{ Indicator } & \multicolumn{5}{|c|}{$x_{1}$} & \multicolumn{4}{|c|}{$x_{2}$} & \multicolumn{3}{|c|}{$x_{3}$} \\
\hline & $x_{11}$ & $x_{12}$ & $x_{13}$ & $x_{14}$ & $x_{15}$ & $x_{21}$ & $x_{22}$ & $x_{23}$ & $x_{24}$ & $x_{31}$ & $x_{32}$ & $x_{33}$ \\
\hline Input & 0.268 & 0.676 & 0.156 & 0.786 & 0.686 & 0.218 & 0.216 & 0.336 & 0.633 & 0.788 & 0.458 & 0.781 \\
\hline
\end{tabular}

TABle 5: Membership degree of building vulnerability indicators.

\begin{tabular}{ccccccc}
\hline \multicolumn{2}{l}{ Indicator } & I & II & III & IV & V \\
\hline \multirow{4}{*}{$x_{1}$} & $x_{11}$ & 0.010 & 0.796 & 0.243 & 0.000 & 0.007 \\
& $x_{12}$ & 0.766 & 0.207 & 0.000 & 0.000 & 0.000 \\
& $x_{13}$ & 0.044 & 0.990 & 0.086 & 0.069 & 0.000 \\
& $x_{14}$ & 0.964 & 0.041 & 0.000 & 0.000 & 0.000 \\
& $x_{15}$ & 0.436 & 0.549 & 0.000 & 0.000 & 0.000 \\
\hline \multirow{4}{*}{$x_{2}$} & $x_{21}$ & 0.000 & 0.000 & 0.010 & 0.983 & 0.007 \\
& $x_{22}$ & 0.000 & 0.000 & 0.027 & 0.971 & 0.002 \\
& $x_{23}$ & 0.000 & 0.000 & 0.129 & 0.747 & 0.162 \\
& $x_{24}$ & 0.000 & 0.000 & 0.29316 & 0.712 & 0.007 \\
\multirow{4}{*}{$x_{3}$} & $x_{31}$ & 0.0007 & 0.345 & 0.670 & 0.005 & 0.000 \\
& $x_{32}$ & 0.000 & 0.0172 & 0.884 & 0.129 & 0.000 \\
& $x_{33}$ & 0.312 & 0.634 & 0.0041 & 0.000 & 0.000 \\
\hline
\end{tabular}

Different from the indicators of building safety and environmental safety, social vulnerability indicators are influenced more strongly by external factors.

(1) Location

Most of the main roads around the area are still the original roads and the surrounding areas have not been developed further; therefore, public transportation around this area is limited. When compared with undeveloped areas, this area has been more highly developed and has a higher population density, but businesses in and around this area are still immature.

(2) Facilities

The infrastructure and living facilities in and around this old industrial area are still under construction and are not satisfactory for living and are still at a high vulnerability level.

(3) Culture

The Shougang Industrial Area was constructed relatively early with the features of strong industrial cultures. Moreover, a number of excellent figures and historical events emerged during the peak production stage, so there is a low cultural vulnerability level.

4.7. Economic Vulnerability Assessment. The assessment input data of social vulnerability indicators were obtained from the local economic statistics and the surrounding economic investigation, as shown in Table 10.

According to NCM, the vulnerability membership degree of each indicator was calculated, as shown in Table 11. The standard normal cloud figure for each index indicator was generated by the forward cloud generator, as shown in Figure 11.
The Shijingshan District has a large economic scale. There are good economic conditions and a relatively high proportion of tertiary industries for reuse in the old industrial area. Therefore, the indicators "economic density" $x_{101}$ and "tertiary industry" $x_{102}$ show a lower vulnerability level. Because of the serious pollution in the industrial area and the demand for a Green Olympics, the owner has adopted stringent measures to deal with pollution and green construction plans. However, these costs are relatively high and there is no better alternative.

4.8. Discussion and Improvement of Vulnerability. According to the vulnerability indicator weights and the vulnerability membership degree obtained from Sections 4.4 to 4.7 , the comprehensive assessment of the vulnerability for reusing the old industrial park is shown in Table 12.

For the building vulnerability indicators, the vulnerability of the indicator "safety" $x_{1}$ is level II tending to level I, the vulnerability of "applicability" $x_{2}$ is level IV tending to level V, and the vulnerability of "durability" $x_{3}$ is level III tending to level II.

For the environmental vulnerability indicators, the vulnerability of "site" $x_{4}$ is level III tending to level IV, the vulnerability of "soil" $x_{5}$ is level II tending to level III, and the vulnerability of "air" $x_{6}$ is level II tending to level III.

For the social vulnerability indicators, the vulnerability of "location" $x_{7}$ is level IV tending to level III, the vulnerability of "facilities" $x_{8}$ is level IV tending to level V, and the vulnerability of "culture" $x_{9}$ is level I tending to level II.

The vulnerability of the indicator "economy" $x_{10}$ is level I tending to level II.

According to the assessment results and the principle of maximum membership degree, the comprehensive vulnerability of this old industrial area for reuse is level IV tending to level III.

(1) Building vulnerability improvement measures

First, strengthening of load-bearing structural members and damaged foundations, and repair of stress cracks shall be completed. Because the vulnerability of the indicator "safety" is low, strengthening of load-bearing structural members shall mainly adopt methods of strengthening with externally bonded reinforced materials and strengthening with wire wrapping; crack repairs shall adopt grouting or caulking, and those that cannot be repaired shall be replaced along with the applicable structural members; strengthening of damaged foundations shall be based on calculations to check-bearing capacities under actual working conditions.

Subsequently, the repair of enclosure structures, replacement of the existing pipe network, and 


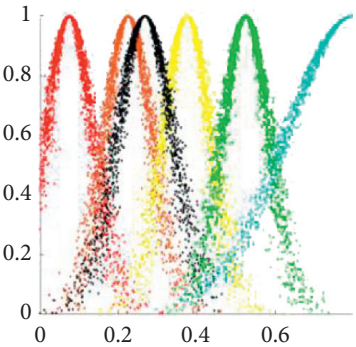

(a)

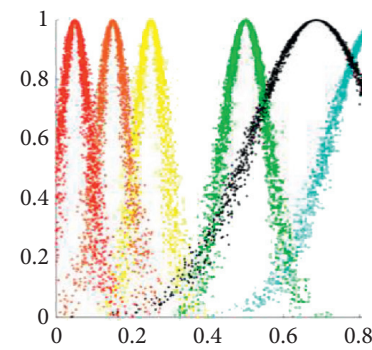

(e)

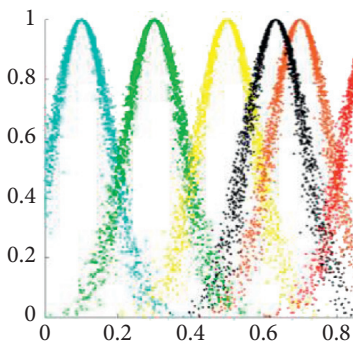

(i)

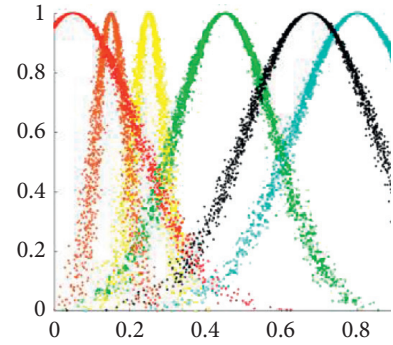

(b)

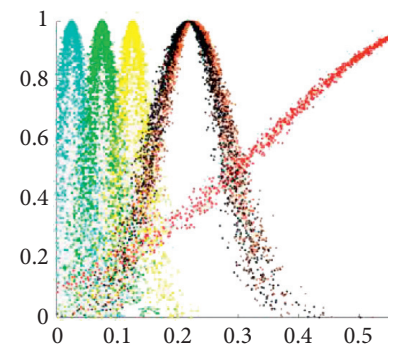

(f)

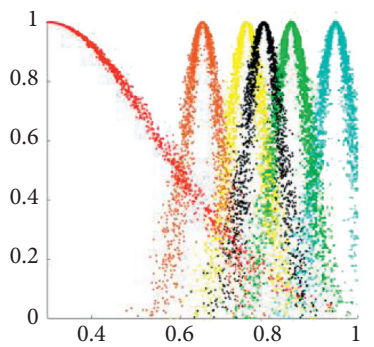

(j)

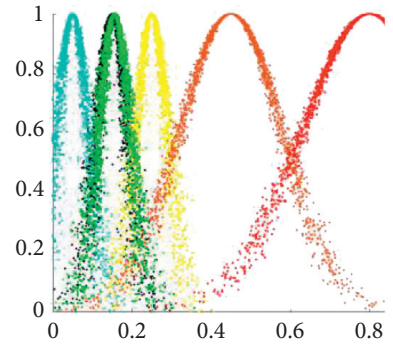

(c)

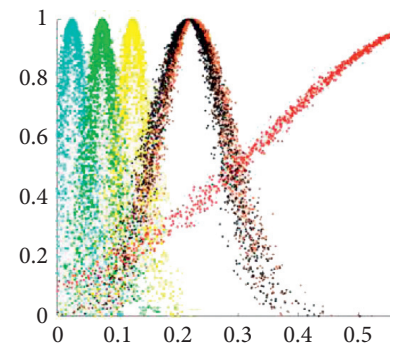

(g)

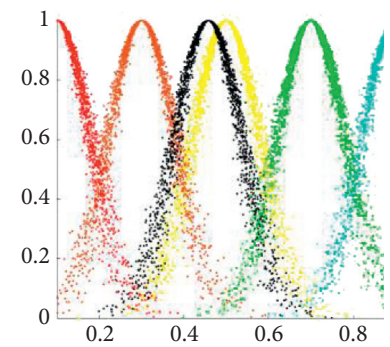

(k)

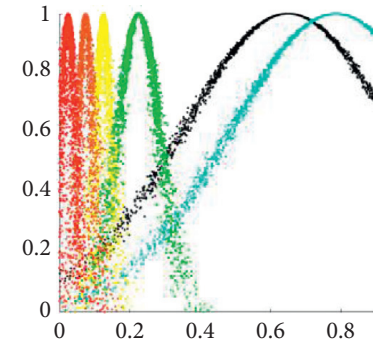

(d)

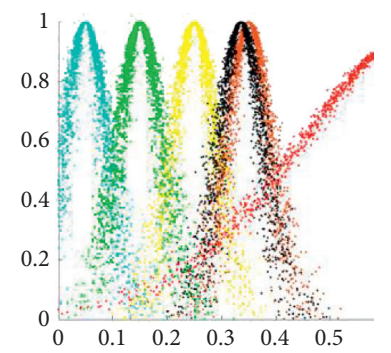

(h)

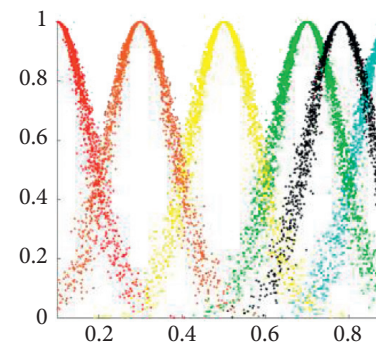

(l)

Figure 8: Cloud figures of building vulnerability (Blue for Level I, Green for Level II, Yellow for Level III, Brown for Level IV, Red for Level $\mathrm{V}$, and Black for assessment value). (a) $x_{11}$. (b) $x_{12}$. (c) $x_{13}$. (d) $x_{14}$. (e) $x_{15}$. (f) $x_{21}$. (g) $x_{22}$. (h) $x_{23}$. (i) $x_{24}$ (j) $x_{31}$. (k) $x_{32}$. (l) $x_{33}$.

TABLE 6: Assessment inputs of environmental vulnerability indicators.

\begin{tabular}{|c|c|c|c|c|c|c|c|c|c|c|c|c|}
\hline \multirow{2}{*}{ Indicator } & \multicolumn{7}{|c|}{$x_{4}$} & \multicolumn{3}{|c|}{$x_{5}$} & \multicolumn{2}{|c|}{$x_{6}$} \\
\hline & $x_{41}$ & $x_{42}$ & $x_{43}$ & $x_{44}$ & $x_{45}$ & $x_{46}$ & $x_{47}$ & $x_{51}$ & $x_{52}$ & $x_{53}$ & $x_{61}$ & $x_{62}$ \\
\hline Input & 0.289 & 31 & 28.8 & 0.382 & 0.318 & 48 & 0.336 & 0.688 & 0.469 & 0.798 & 2.883 & 0.709 \\
\hline
\end{tabular}

TABLE 7: Membership degree of environmental vulnerability indicators.

\begin{tabular}{|c|c|c|c|c|c|c|}
\hline \multicolumn{2}{|c|}{ Indicator } & I & II & III & IV & $\mathrm{V}$ \\
\hline \multirow{7}{*}{$x_{4}$} & $x_{41}$ & 0.094 & 0.425 & 0.655 & 0.004 & 0.000 \\
\hline & $x_{42}$ & 0.000 & 0.000 & 0.998 & 0.116 & 0.000 \\
\hline & $x_{43}$ & 0.000 & 0.838 & 0.0989 & 0.000 & 0.000 \\
\hline & $x_{44}$ & 0.000 & 0.000 & 0.007 & 0.552 & 0.458 \\
\hline & $x_{45}$ & 0.000 & 0.000 & 0.277 & 0.352 & 0.324 \\
\hline & $x_{46}$ & 0.034 & 0.641 & 0.368 & 0.000 & 0.000 \\
\hline & $x_{47}$ & 0.029 & 0.027 & 0.947 & 0.0190 & 0.000 \\
\hline \multirow{3}{*}{$x_{5}$} & $x_{51}$ & 0.000 & 0.000 & 0.174 & 0.8046 & 0.001 \\
\hline & $x_{52}$ & 0.075 & 0.996 & 0.071 & 0.000 & 0.000 \\
\hline & $x_{53}$ & 0.001 & 0.473 & 0.528 & 0.002 & 0.001 \\
\hline \multirow{2}{*}{$x_{6}$} & $x_{61}$ & 0.004 & 0.889 & 0.109 & 0.000 & 0.000 \\
\hline & $x_{62}$ & 0.000 & 0.563 & 0.438 & 0.001 & 0.000 \\
\hline
\end{tabular}




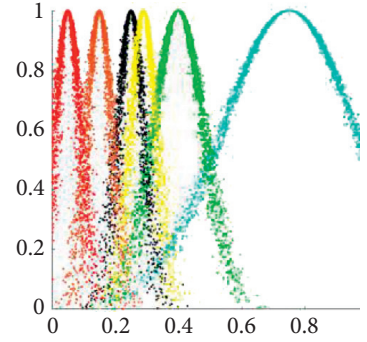

(a)

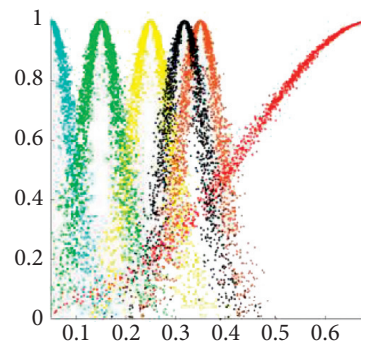

(e)

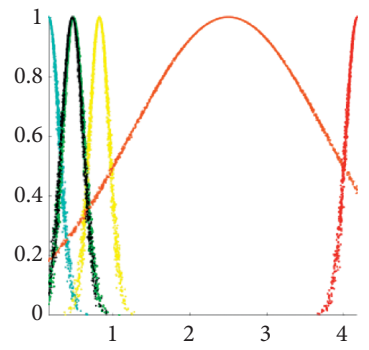

(i)

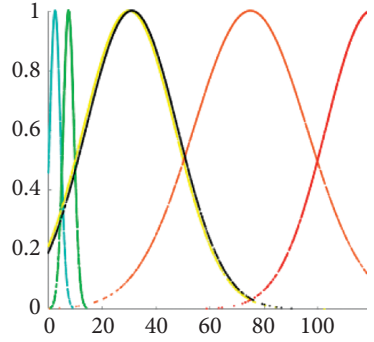

(b)

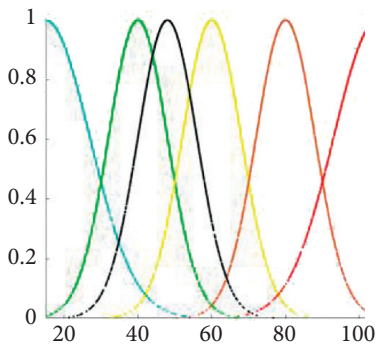

(f)

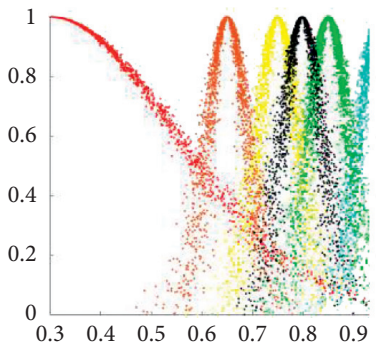

(j)

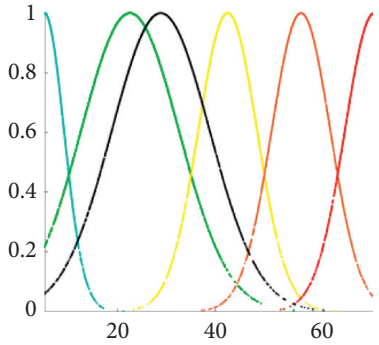

(c)

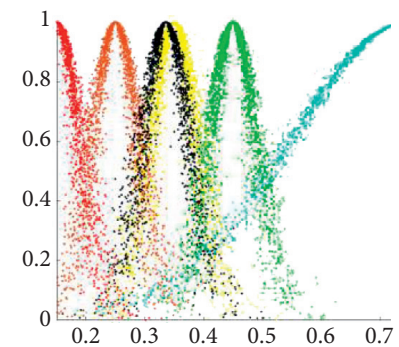

(g)

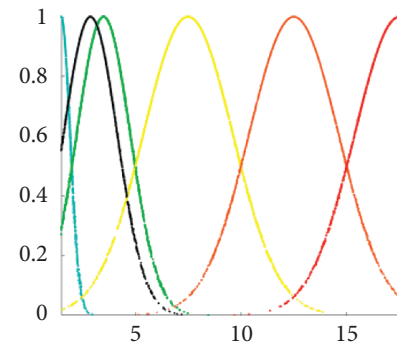

(k)

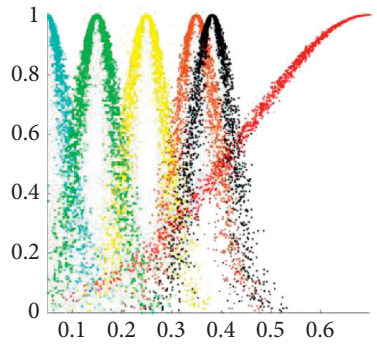

(d)

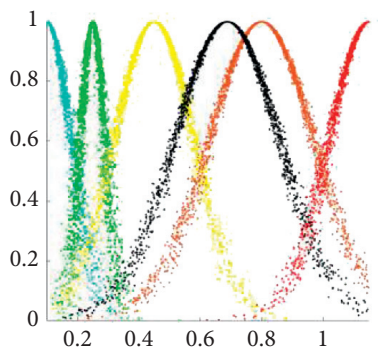

(h)

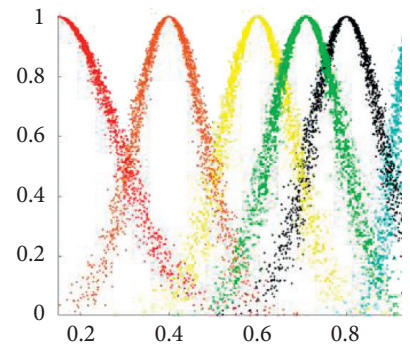

(l)

FIgure 9: Cloud figures for environmental vulnerability (Blue for Level (I), Green for Level II, Yellow for Level III, Brown for Level IV, Red for Level (V), and Black for assessment value). (a) $x_{41}$. (b) $x_{42}$. (c) $x_{43}$. (d) $x_{44}$. (e) $x_{45}$. (f) $x_{46}$. (g) $x_{47}$. (h) $x_{51}$. (i) $x_{52}$. (j) $x_{52}$. (k) $x_{61}$. (l) $x_{62}$.

TABLE 8: Assessment inputs of social vulnerability indicators.

\begin{tabular}{lccccccc}
\hline Indicator & & & & & $x_{8}$ & $x_{9}$ \\
& $x_{71}$ & $x_{72}$ & $x_{73}$ & $x_{74}$ & $x_{81}$ & $x_{91}$ \\
\hline Input & 3.18 & 8 & 112 & 0.118 & 0.126 & 0.184 \\
\hline
\end{tabular}

reinforcement of structural strength should be completed. Repair of enclosure structures should comply with the requirements of the planning and design of the park; the existing pipe network should be replaced based on reuse of some pipe networks and the replaced materials should meet the design requirements of the pipe network; since the structures that meet the strength requirements account for a large proportion, only a few structures should be reinforced to the relevant specifications after the replacement or strengthening of the load-bearing structural members.

(2) Environmental vulnerability improvement measures Surrounding polluting factories and air quality are both external factors and cannot be self-improved; indoor air quality will be improved by changing the building door and window types, and by installing adequate indoor air purifiers; landscaping should be prepared more to form a microclimate environment to compensate for the external insufficiencies. Thermal desorption can be used for remediation of the concentrated heavily polluted soil and groundwater, but protective measures for excavation and transportation should be given sufficient attention after the polluted soil is treated.

(3) Socioeconomic vulnerability improvement measures To improve the social vulnerability of this old industrial area, the planning and design of the park should be adjusted, and public facilities and business opportunities around the park should be properly enhanced. The current funding model is mainly from a single source, namely, from subsidies of the Beijing Municipal Government. This model should be changed, and increasing social capital investment in 
TABLE 9: Membership degree of social vulnerability indicators.

\begin{tabular}{|c|c|c|c|c|c|c|}
\hline \multicolumn{2}{|c|}{ Indicator } & I & II & III & IV & $\mathrm{V}$ \\
\hline \multirow{4}{*}{$x_{7}$} & $x_{71}$ & 0.000 & 0.007 & 0.7526 & 0.277 & 0.037 \\
\hline & $x_{72}$ & 0.000 & 0.001 & 0.499 & 0.499 & 0.001 \\
\hline & $x_{73}$ & 0.670 & 0.319 & 0.000 & 0.000 & 0.000 \\
\hline & $x_{74}$ & 0.073 & 0.000 & 0.007 & 0.752 & 0.237 \\
\hline \multirow{2}{*}{$x_{8}$} & $x_{81}$ & 0.079 & 0.000 & 0.014 & 0.852 & 0.132 \\
\hline & $x_{82}$ & 0.002 & 0.000 & 0.054 & 0.864 & 0.231 \\
\hline$x_{9}$ & $x_{91}$ & 0.840 & 0.130 & 0.030 & 0.000 & 0.000 \\
\hline
\end{tabular}

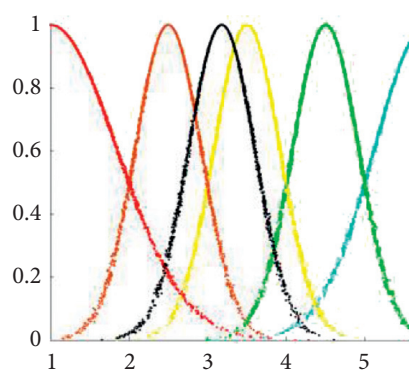

(a)

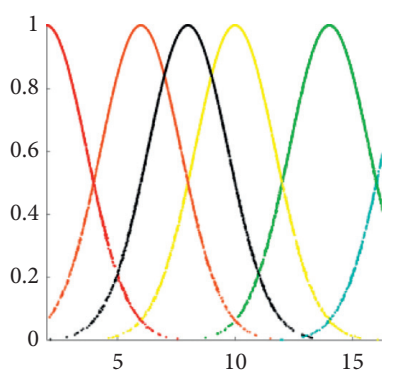

(b)

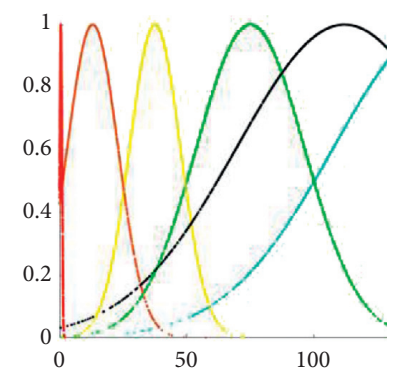

(c)

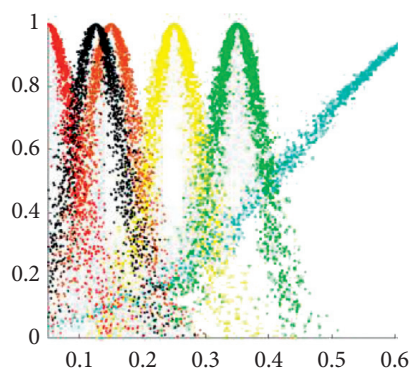

(d)

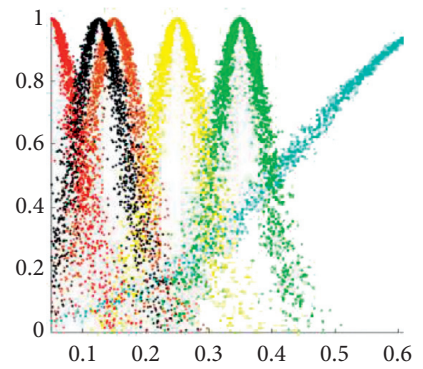

(e)

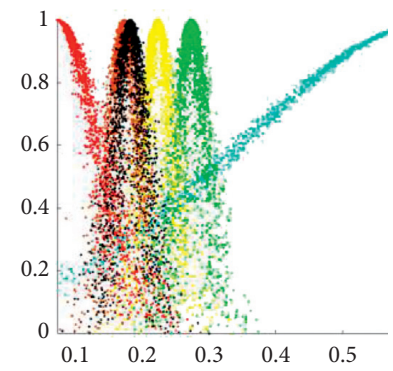

(f)

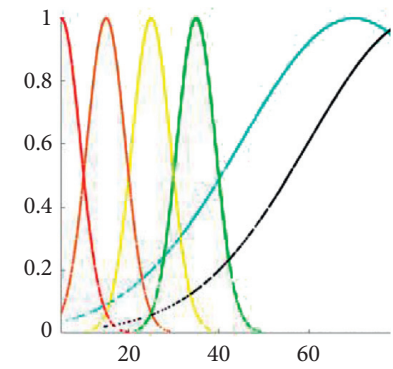

(g)

Figure 10: Cloud figures of social vulnerability (Blue for Level I, Green for Level II, Yellow for Level III, Brown for Level IV, Red for Level V, and Black for assessment value). (a) $x_{71}$. (b) $x_{72}$. (c) $x_{73}$. (d) $x_{74}$. (e) $x_{81}$. (f) $x_{82}$. (g) $x_{91}$.

TABLE 10: Assessment inputs of economic vulnerability indicators.

\begin{tabular}{|c|c|c|c|c|}
\hline \multirow{2}{*}{ Indicator } & \multicolumn{4}{|c|}{$x_{10}$} \\
\hline & $x_{101}$ & $x_{102}$ & $x_{103}$ & $x_{104}$ \\
\hline Input & 9.8 & 0.725 & 0.236 & 0.203 \\
\hline
\end{tabular}

TABLE 11: Membership degree of social vulnerability indicators.

\begin{tabular}{|c|c|c|c|c|c|c|}
\hline \multicolumn{2}{|c|}{ Indicator } & I & II & III & IV & $\mathrm{V}$ \\
\hline \multirow{4}{*}{$x_{10}$} & $x_{101}$ & 0.993 & 0.007 & 0.000 & 0.000 & 0.000 \\
\hline & $x_{102}$ & 0.993 & 0.006 & 0.000 & 0.000 & 0.000 \\
\hline & $x_{103}$ & 0.002 & 0.027 & 0.947 & 0.028 & 0.000 \\
\hline & $x_{104}$ & 0.000 & 0.000 & 0.002 & 0.520 & 0.479 \\
\hline
\end{tabular}




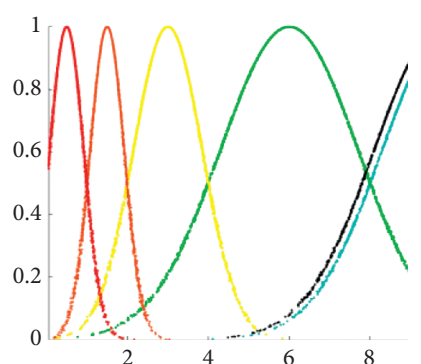

(a)

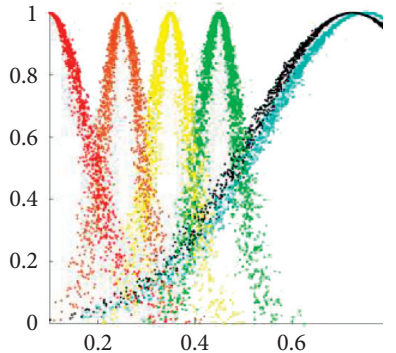

(b)

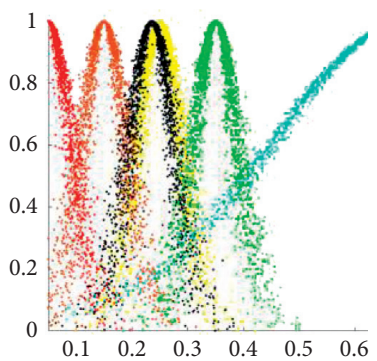

(c)

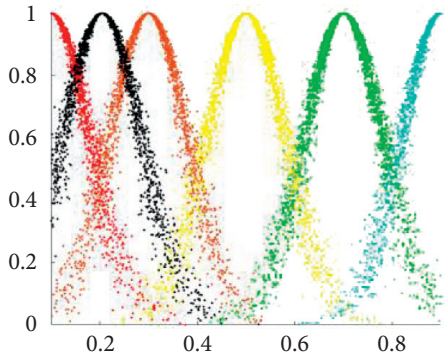

(d)

Figure 11: Cloud figures of economic vulnerability (Blue for Level, I Green for Level II, Yellow for Level III, Brown for Level IV, Red for Level V, and Black for assessment value). (a) $x_{101}$. (b) $x_{102}$. (c) $x_{103}$. (d) $x_{104}$.

TABLE 12: The comprehensive assessment level of the vulnerability.

\begin{tabular}{lccccc}
\hline Indicator & Weights & I & II & III & IV \\
\hline$x_{1}$ & 0.104 & 0.427 & 0.471 & 0.067 & 0.008 \\
$x_{2}$ & 0.086 & 0.000 & 0.000 & 0.071 & 0.694 \\
$x_{3}$ & 0.118 & 0.097 & 0.307 & 0.571 & 0.001 \\
$x_{4}$ & 0.098 & 0.028 & 0.140 & 0.422 & 0.301 \\
$x_{5}$ & 0.125 & 0.021 & 0.451 & 0.276 & 0.329 \\
$x_{6}$ & 0.064 & 0.003 & 0.783 & 0.206 & 0.362 \\
$x_{7}$ & 0.108 & 0.172 & 0.050 & 0.293 & 0.000 \\
$x_{8}$ & 0.102 & 0.002 & 0.005 & 0.087 & 0.413 \\
$x_{9}$ & 0.101 & 0.840 & 0.130 & 0.030 & 0.884 \\
$x_{10}$ & 0.094 & 0.608 & 0.040 & 0.271 & 0.000 \\
Comprehensive assessment & 1 & 0.222187 & 0.228217 & 0.238514 & 0.000 \\
\hline
\end{tabular}

the park to improve economic vulnerability would be ideal. In addition, environmental protection measures should be appropriately adjusted to reduce costs and improve the vulnerability.

\section{Conclusion}

Disposal of old industrial areas has become a serious problem in urban renewal while reuse has already become an important solution. However, the structural damage to existing industrial buildings and environmental pollution has negative impacts on the vulnerability of old industrial areas. The purpose of vulnerability analysis for reusing old industrial areas is to comprehensively assess the vulnerability level of their buildings, environment, society, and economy under adverse conditions, and to provide a reliable basis for improving the vulnerabilities.

(1) Similar to safety assessments or sustainability assessments, there are various uncertainties, randomness, and fuzziness in vulnerability assessments for reusing old industrial areas. NCM not only can fully consider the fuzziness and randomness but can also achieve the conversion between qualitative and quantitative variables. Therefore, NCM was adopted as the vulnerability assessment model in this study, which was also the basis for the assessment process, so that reasonable and accurate assessment results could be obtained.

(2) The vulnerability assessment indicators for reusing old industrial areas should give expression to the vulnerabilities that exist during the entire process of decision-making, design, construction, and operation. Moreover, they should reflect the vulnerability trends. Different from common vulnerability assessment indicator systems, this study constructs a modified vulnerability assessment indicator system that consists of four parts including building vulnerability as well as environment, society, and economy after indicator optimization. Optimizing these assessment indicators under the concept of NCM can reduce the possibility of subjective influences.

(3) In the Shougang Industrial Area, which will be reused as the Winter Olympic Park, the basic data for the vulnerability assessment were collected from testing reports and investigations. Furthermore, the vulnerability membership degree of each assessment indicator was calculated based on NCM, and normal cloud figures were generated by the forward cloud generator, which can directly reflect the vulnerability 
level of each assessment indicator. Finally, effective measures to improve the vulnerability under reuse were developed based on the results of a vulnerability assessment.

\section{Data Availability}

All data used to support the findings of this study are available from the corresponding author upon request.

\section{Conflicts of Interest}

The authors declare that they have no conflicts of interest.

\section{Acknowledgments}

The authors sincerely thank the Shougang Group for providing data support for this study and are grateful for the assistance of experts of the Delphi and IAHP panel. This work was financially supported by the National Natural Science Foundation of China (Grant no. 51908452) and Special Scientific Research Plan of Education Department of Shaanxi Province (Grant no. 18JK0470).

\section{References}

[1] S. J. Fan, J. X. Sheng, H. M. Li, and R. Q. Yan, "Potential assessment of old industrial buildings reuse utilization based on combination weight method," Industrial Construction, vol. 10, no. 2, 2013.

[2] H. M. Li, W. Tian, and R. Q. Yan, "Constituting recycling assessment indicator system for old industrial buildings (group)," Journal of Xi'an University of Architecture and Technology (Natural Science Edition), vol. 6, Article ID 772, 2013.

[3] Y. Hashempour, M. Nasseri, A. Mohseni-Bandpei, S. Motesaddi, and M. Eslamizadeh, "Assessing vulnerability to climate change for total organic carbon in a system of drinking water supply," Sustainable Cities and Society, vol. 53, Article ID 101904, 2020.

[4] P. Wang, W. Qiao, Y. Wang, S. Cao, and Y. Zhang, "Urban drought vulnerability assessment-a framework to integrate socio-economic, physical, and policy index in a vulnerability contribution analysis," Sustainable Cities and Society, vol. 54, Article ID 102004, 2020.

[5] D. B. Karakoc, K. Barker, C. W. Zobel, and Y. Almoghathawi, "Social vulnerability and equity perspectives on interdependent infrastructure network component importance," Sustainable Cities and Society, vol. 57, Article ID 102072, 2020.

[6] S. Z. Zhang, "Vulnerability evaluation of Daqing's urbanization based on normal cloud model," Resources \& Industries, vol. 20, no. 5, pp. 53-60, 2018.

[7] Q. Liu, M. Wang, X. Wang, F. Shen, and J. Jin, "Land eco-security assessment based on the multi-dimensional connection cloud model," Sustainability, vol. 10, no. 6, p. 2096, 2018.

[8] Z. Wang, X. Deng, C. Wong, Z. Li, and J. Chen, "Learning urban resilience from a social-economic-ecological system perspective: a case study of Beijing from 1978 to 2015," Journal of Cleaner Production, vol. 183, pp. 343-357, 2018.

[9] L. Zhang, Y. Geng, H. Dong et al., "Emergy-based assessment on the brownfield redevelopment of one old industrial area: a case of Tiexi in China," Journal of Cleaner Production, vol. 114, pp. 150-159, 2016.

[10] H. Luan, J. Law, and M. Lysy, "Diving into the consumer nutrition environment: a Bayesian spatial factor analysis of neighborhood restaurant environment," Spatial and Spatio-Temporal Epidemiology, vol. 24, pp. 39-51, 2018.

[11] J. Liu, F. Xu, and S. Lin, "Site selection of photovoltaic power plants in a value chain based on grey cumulative prospect theory for sustainability: a case study in Northwest China," Journal of Cleaner Production, vol. 148, pp. 386-397, 2017.

[12] S. Lee, W. Han, and Y. Park, "Measuring the functional dynamics of product-service system: a system dynamics approach," Computers \& Industrial Engineering, vol. 80, pp. 159-170, 2015.

[13] J.-H. Yoon and K.-h. Sim, "Why is South Korea's renewable energy policy failing? A qualitative evaluation," Energy Policy, vol. 86, pp. 369-379, 2015.

[14] B. Wang, H.-N. Li, X.-C. Yuan, and Z.-M. Sun, "Energy poverty in China: a dynamic analysis based on a hybrid panel data decision model," Energies, vol. 10, no. 12, p. 1942, 2017.

[15] D. Liang and $\mathrm{Z}$. Xu, "The new extension of TOPSIS method for multiple criteria decision making with hesitant Pythagorean fuzzy sets," Applied Soft Computing, vol. 60, pp. 167$179,2017$.

[16] X. Zhao, H. Sun, B. Chen, X. Xia, and P. Li, "China's rural human settlements: qualitative evaluation, quantitative analysis and policy implications," Ecological Indicators, vol. 105, pp. 398-405, 2018.

[17] D. Li and Y. Du, Artificial Intelligence with Uncertainty, CRC Press, Boca Raton, FL, USA, 2005.

[18] X. T. Wang, S. C. Li, Z. H. Xu, J. Hu, D. D. Pan, and Y. G. Xue, "Risk assessment of water inrush in karst tunnels excavation based on normal cloud model," Bulletin of Engineering Geology and the Environment, vol. 78, pp. 3786-3798, 2019.

[19] D. Wang, D. Zeng, V. P. Singh et al., "A multidimension cloud model-based approach for water quality assessment," Environmental Research, vol. 149, pp. 113-121, 2016.

[20] C.-Q. Cui, B. Wang, Y.-X. Zhao, Q. Wang, and Z.-M. Sun, "China's regional sustainability assessment on mineral resources: results from an improved analytic hierarchy process-based normal cloud model," Journal of Cleaner Production, vol. 210, pp. 105-120, 2019.

[21] Y. Zhang, F. Zhang, H. Zhu, and P. Guo, "An optimization-evaluation agricultural water planning approach based on interval linear fractional Bi-level programming and IAHP-TOPSIS," Water, vol. 11, no. 5, p. 1094, 2019. 